
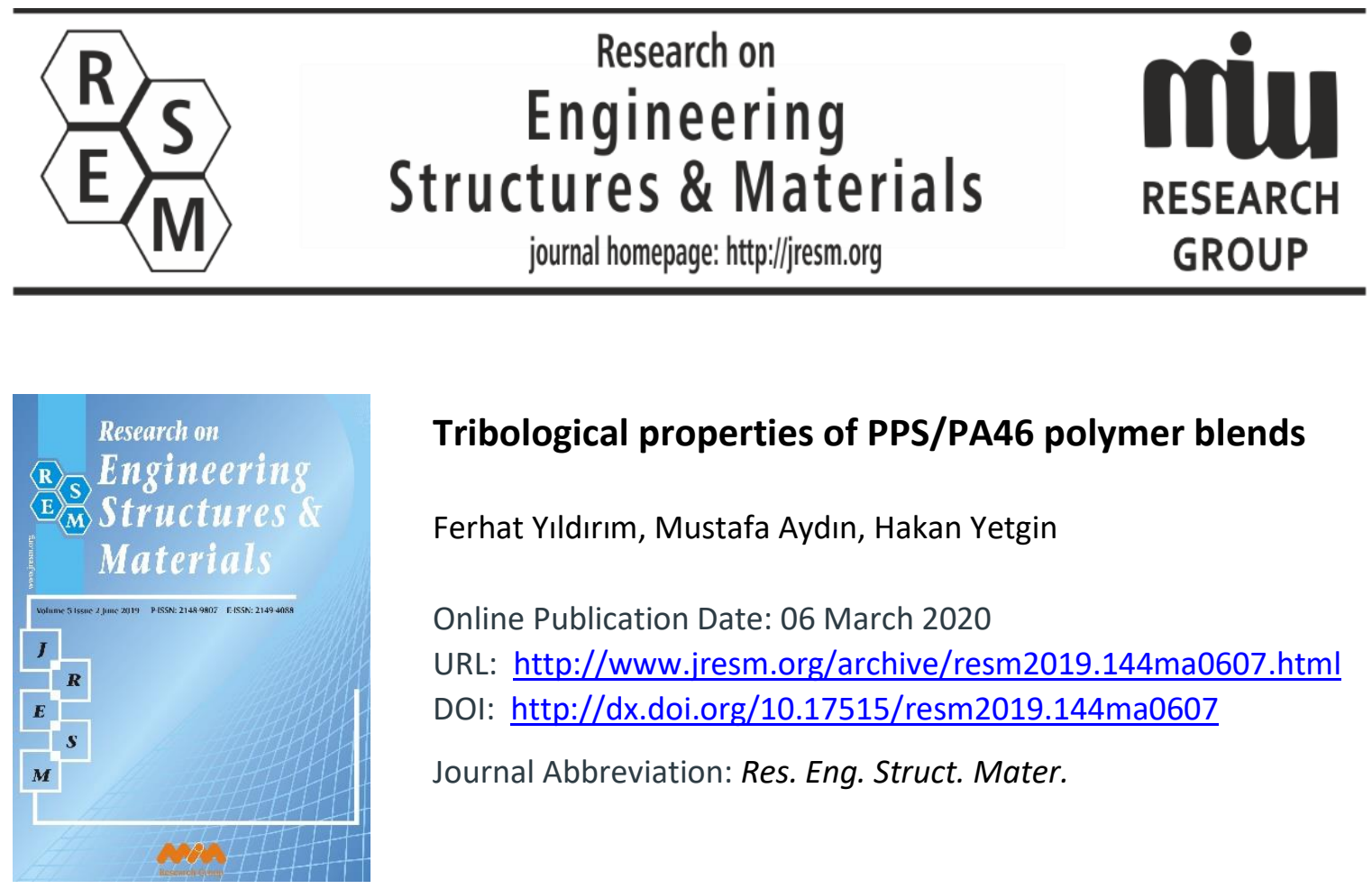

\title{
Tribological properties of PPS/PA46 polymer blends
}

Ferhat Yıldırım, Mustafa Aydın, Hakan Yetgin

Online Publication Date: 06 March 2020

URL: http://www.jresm.org/archive/resm2019.144ma0607.html

DOI: http://dx.doi.org/10.17515/resm2019.144ma0607

Journal Abbreviation: Res. Eng. Struct. Mater.

\section{To cite this article}

Yildirim F, Aydin M, Yetgin H. Tribological properties of PPS/PA46 polymer blends. Res. Eng. Struct. Mater., 2020; 6(3): 271-282.

\section{Disclaimer}

All the opinions and statements expressed in the papers are on the responsibility of author(s) and are not to be regarded as those of the journal of Research on Engineering Structures and Materials (RESM) organization or related parties. The publishers make no warranty, explicit or implied, or make any representation with respect to the contents of any article will be complete or accurate or up to date. The accuracy of any instructions, equations, or other information should be independently verified. The publisher and related parties shall not be liable for any loss, actions, claims, proceedings, demand or costs or damages whatsoever or howsoever caused arising directly or indirectly in connection with use of the information given in the journal or related means.

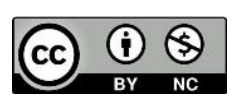

Published articles are freely available to users under the terms of Creative Commons Attribution - NonCommercial 4.0 International Public License, as currently displayed at here (the "CC BY - NC"). 


\title{
Research on Engineering Structures \& Materials
}

journal homepage: http://jresm.org

Research Article

\section{Tribological properties of PPS/PA46 polymer blends}

\author{
Ferhat Yıldırım*1,a, Mustafa Aydın²,b, Hakan Yetgin ${ }^{3, c}$ \\ ${ }^{1}$ Machinery and Metal Technologies Department, Biga Vocational School, Çanakkale Onsekiz Mart University, \\ Çanakkale, Turkey \\ ${ }_{2}^{2}$ Mechanical Engineering Department, Hasan Ferdi Turgutlu Technologie Faculty, Manisa Celal Bayar \\ University, Manisa, Turkey \\ ${ }^{3}$ Mechanical Engineering Department, Simav Technologie Faculty, Kütahya Dumlupınar University, Kütahya, \\ Turkey

\begin{tabular}{|c|c|}
\hline rticle Info & Abstract \\
\hline $\begin{array}{l}\text { rticle history: } \\
\text { eceived 07Aug } 2019 \\
\text { evised01 Mar } 2020 \\
\text { ccepted } 02 \text { Mar } 2020\end{array}$ & $\begin{array}{l}\text { In this study, the tribological performance of originally } 40 \mathrm{wt} . \% \text { fiber glass } \\
\text { reinforced polyphenylene sulfide (PPS-G), polyamide } 46 \text { (PA46) and their blends } \\
\text { were studied at dry sliding conditions. The materials were mixed and extruded } \\
\text { on the twin screw extruder. The blends were dried and tribological test } \\
\text { specimens were manufactured by using the injection machine. Wear tests were }\end{array}$ \\
\hline $\begin{array}{l}\text { Keywords: } \\
\text { Fiber Glass } \\
\text { Reinforcement; } \\
\text { Hybrid Composite; } \\
\text { Polyamide 46; } \\
\text { Polyphenylene Sulfide; }\end{array}$ & $\begin{array}{l}\text { steel disc. Test conditions were atmospheric conditions having } 60,90,120 \mathrm{~N} \\
\text { loads and } 0.5,1.0,1.5 \mathrm{~m} / \mathrm{s} \text { sliding speeds. The obtained results proved that the } \\
\text { coefficient of friction for PPS-G, PA } 46 \text { and their blends is decrease while the } \\
\text { applied load and sliding speed values are increase. On the other hand, the specific } \\
\text { wear rate is in increase while the applied load and sliding speed values are in } \\
\text { increase. }\end{array}$ \\
\hline
\end{tabular}

(C) 2020 MIM Research Group. All rights reserved.

\section{Introduction}

Polyphenylene sulfide (PPS) is a semi crystalline high-performance engineering thermoplastic polymer with excellent properties such as high temperature performance, heat resistance, chemical resistance, electrical insulation, high dimensional stability, good mechanical properties and flame retardancy without additives [1-5]. This property of PPS makes it popular in various applications including electronics and electrical appliances, automobile, chemical sector and aerospace [6-10]. However, the application of PPS has been limited due to its relatively low glass transition temperature $\left(\sim 90^{\circ} \mathrm{C}\right)$, rather brittle with a low elongation at break and high cost $[1,2,5,7,8,11,12]$. In order to overcome these problems, PPS was blended with other polymers or reinforced with rigid particles $[5,11]$. Polyamides (PAs) such as PA6, PA46 and PA66 are generally investigated for their wear performance $[4,12-14]$. Among them, the chemical structure of PA46 offers an advantage compared to PA6 and PA66 [15].

The tribological performance of polymers and polymer blends are directly related to the test parameters like loads, sliding speed and distance and transfer film properties $[16,17]$. The effect of test conditions on friction and wear behavior properties of PA, PPS and their composites have been reported in earlier papers $[4,12,18]$. Chen et al. [12] investigated the mechanical and tribological properties of PA66 and PPS blends. Tribological test was performed under ambient conditions at a speed of $0.42 \mathrm{~m} / \mathrm{s}$ and a normal load of $196 \mathrm{~N}$.

\footnotetext{
${ }^{*}$ Correspondingauthor: ferhatyildirim@comu.edu.tr

a orcid.org/0000-0002-0524-4050; ${ }^{b}$ orcid.org/0000-0002-9150-4081; c orcid.org/0000-0002-6068-9204 DOI: http://dx.doi.org/10.17515/resm2019.144ma0607
}

Res. Eng. Struct. Mat. Vol. 6 Iss. 3 (2020) 271-282 
They pointed out that the minimum wear volume was obtained in the case of PA66/PPS $(80 / 20)$ blend and the wear volume of blends increased with PPS proportion after the PPS content exceeds $20 \mathrm{vol}$. \%. Zhou et al. [4] investigated the effect of carbon fiber (CF) on mechanical and tribological performance of the PA6/PPS composites. The friction and wear tests were carried out under $10 \mathrm{~N}, 15 \mathrm{~N}$ and $20 \mathrm{~N}$ loads and 500, 1000 and 1500 $\mathrm{rpm} / \mathrm{min}$ rotate speeds, for a duration of $40 \mathrm{~min}$. Under the friction condition of high applied load or high sliding speed, friction coefficient of the PA6/PPS-CF composites tends to decrease, and wear rate tends to increase. Zhao and Bahadur [18] investigated the tribological behaviors of the particulates $\mathrm{NiS}$ and PbSe filled polyphenylene sulfide (PPS) composites under ambient conditions in a pin-on-disk configuration at a sliding speed of $1.0 \mathrm{~m} / \mathrm{s}$ and a nominal pressure of $0.65 \mathrm{MPa}$. Cho [19] studied the role of transfer films formed during the sliding of PPS/CuO/CF/Kevlar polymer composites against the steel counter face. It was reported that as far as the transfer film became smooth and uniform, the wear rate decreased. Cho et al. [20] studied the tribological behavior of molybdenumconcentrate (MC) filled polyphenylene sulfide (PPS). They reported that MC, as the filler in particulate form, reduced the steady state wear rate of PPS, and the optimum reduction in wear was found to occur with the addition of polytetrafluroethylene (PTFE) along with PPS. Cong et al. [13] investigated the tribological properties of PA46/HDPE poly blend with different component ratios. They reported that HDPE was effective in reducing the friction coefficient of PA46 and specific wear rate of PA46/HDPE poly blend decreased with increasing HDPE content. Scherge et al. [14] investigated the wear characteristics of aliphatic PA 46 on lubricated steel disk. They declared that under certain boundary parameters at transfer film forms and significantly improvement wear performance. Yu et al. [21] studied the friction and wear behaviors of polyamide 66 (PA 66) and rubber-filled PA 66 (PA 66/SEBS- $g$-MA) composites on a block-on-wheel model friction and wear tester under dry sliding and water lubricating conditions. The friction coefficients of PA 66 and PA 66/SEBS- $g$-MA composites under water lubricating condition were lower than those under dry sliding condition, but the wear mass losses were higher than those under dry sliding condition. It is seen from the literature that the majority of the investigations confined their discussions to dry sliding condition.

It is known that high thermal resistant polymer such as PPS and PA46 are used in automotive industry as products (such as fuel injection systems, air intake manifold, coolant systems, water pump impellers, thermostat holder, electric brakes, switches, bulb housing and so on) that work under the effects of temperature and pressure [22-25]. And, at the same time, they remain in constant friction with other metal and polymer materials with which they are in contact, both due to engine vibration and road shock. Although their usage is increasingly widespread there is no enough study about on the tribological properties of PA/PPS polymer blends. So, in this study these two high temperature polymers that are widely used in industry are selected and the influence of sliding speed and load values on the friction and wear characteristics of PA46, PPS-G (originally glass fiber reinforced PPS) and their blends were studied.

\section{Material and Method}

The selected materials polyamide 46 (Stanyl PA46) with $1.18 \mathrm{~g} / \mathrm{cm}^{3}$ density was supplied from Royal DSM (Holland) and $40 \mathrm{wt}$ \% glass fiber filled PPS (PPS S25G40) with $1.57 \mathrm{~g} / \mathrm{cm}^{3}$ density was supplied from Kolon Plastic Inc. (China). PPS/PA46 blends were manufactured on AYSA LAB30 model, was given in Fig. 1.a, co-rotating double screw extruder machine in the following volume ratios: $100 / 0 ; 90 / 10 ; 80 / 20 ; 50 / 50$ and $0 / 100$. The extruder temperatures from the feed zone of polymer to the exit die were 275, 280, 288, 295 and $300{ }^{\circ} \mathrm{C}$, respectively. The extruder exit die diameter is $4 \mathrm{~mm}$ and the screw speed was 70 $\mathrm{rpm}$. The polymers were dehumidified at $140^{\circ} \mathrm{C}$ for 4 hours before extrusion. The extruded 
polymer mix material pelletized in the crusher. Thereafter, the injected samples (Fig.1.c) for wear tests were produced using the injection machine Demag Stübbe S110, which was given in Fig. 1.b at 500 bar injection pressure. The injection temperatures from the feed zone to the exit nozzle were $275,285,295,300$ and $300{ }^{\circ} \mathrm{C}$. The screw speed was $80 \mathrm{~cm}^{3} / \mathrm{s}$ and the mould temperature was $30^{\circ} \mathrm{C}$.
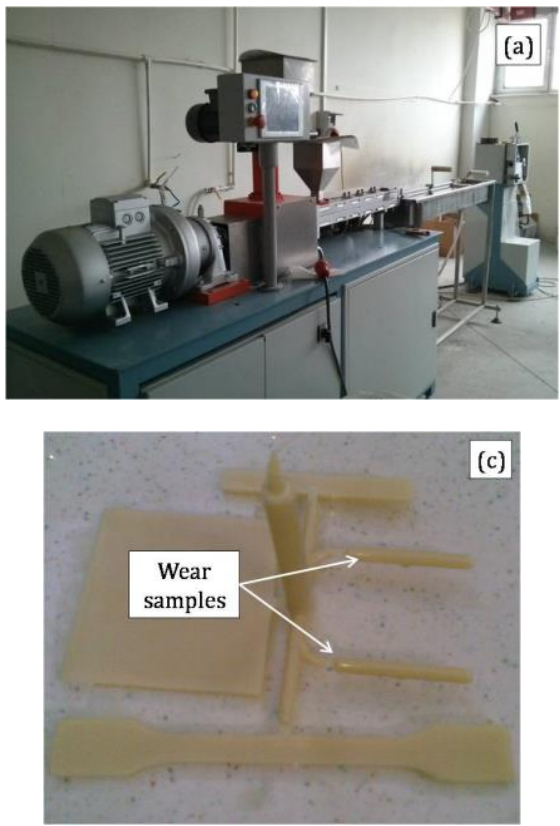
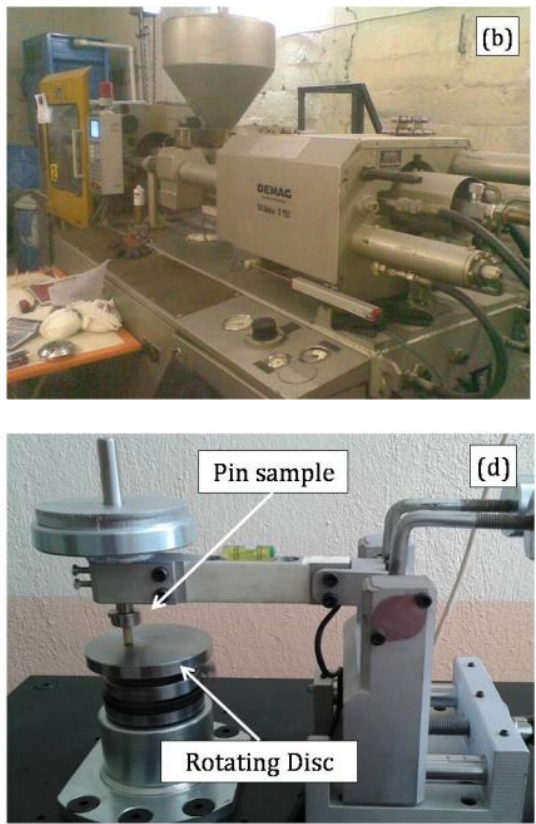

Fig.1.a) AYSA LAB30 co-rotating twin-screw extruder, b) DemagStübbe S110 injectionmolding machine, c) Injected test samples, d) Pin-on-disc wear test rig.

Fig. 1.d shows the pin-on-disc wear test rig. The wear tests were performed at room temperature with non-lubrication or any wetting system. Materials and the specific test conditions (i.e. materials, ambient temperature, applied load, sliding speed and humidity) selected for this study were summarized in Table 1.

Table 1 Properties and specific test parameters of the PPS-40GF, PA46 and their blends.

\begin{tabular}{cccccc}
\hline Materials & $\begin{array}{c}\text { Density } \\
\left(\mathrm{g} / \mathrm{cm}^{3}\right)\end{array}$ & $\begin{array}{c}\text { Applied } \\
\text { load }(\mathrm{N})\end{array}$ & $\begin{array}{c}\text { Sliding } \\
\text { speed } \\
(\mathrm{mm} / \mathrm{s})\end{array}$ & $\begin{array}{c}\text { Temperature } \\
\left({ }^{\circ} \mathrm{C}\right)\end{array}$ & $\begin{array}{c}\text { Humidity } \\
(\%)\end{array}$ \\
\hline PPS-G & 1.57 & & & & \\
PPS-G/10\%PA46 & 1.51 & & & & \\
PPS-G/20\%PA46 & 1.42 & $60,90,120$ & $0.5,1.0,1.5$ & $22 \pm 3$ & $50 \pm 5$ \\
PPS-G/50\%PA46 & 1.34 & & & & \\
PA46 & 1.18 & & & & \\
\hline
\end{tabular}

As is known, polymer materials generally work against metal materials in terms of their use. Therefore, in this study, medium carbon steel (AISI 1040) material was chosen as the counter disc surface. The disc of the wear test rig had $100 \mathrm{~mm}$ diameter and $5 \mathrm{~mm}$ thickness. The cylindrical polymer pin samples had $5 \mathrm{~mm}$ diameter and $50 \mathrm{~mm}$ length. Before the wear test, the samples contact surfaces were processed at 1000 grade paper. In addition, both disc and sample surfaces were cleaned with alcohol and then dried quickly. 
All tests were performed in three times and their averages results were taken. The average mass loss in the pin was measured and the specific wear rates were calculated.

\section{Results and Discussion}

Table 2 gives the coefficient of friction results for PPS-G, PPS-G/10\%PA46, PPSG/20\%PA46, PPS-G/50\%PA46 and PA46 polymers according to the test parameters. The coefficient of friction is expressed as the ratio of lateral force to normal applied force and is calculated by Eq. 1 .

$$
\mu=\frac{F_{S}}{F_{N}}
$$

Here; $\mu$ is friction coefficient, $F_{S}$ is lateral friction force and $F_{N}$ is normal applied force.

Table 2 Average coefficient of friction values for PPS-G, PPS-G/10\%PA46, PPSG/20\%PA46, PPS-G/50\%PA46 and PA46 polymers tested at different load and sliding speed values.

\begin{tabular}{ccccc}
\hline & & \multicolumn{3}{c}{ Sliding speed $(\mathrm{m} / \mathrm{s})$} \\
\cline { 3 - 5 } Materials & $(\mathrm{N})$ & 0.5 & 1.0 & 1.5 \\
\cline { 3 - 5 } & 60 & 0.2853 & 0.2601 & 0.2495 \\
PPS-G & 90 & 0.2784 & 0.2248 & 0.1956 \\
& 120 & 0.2566 & 0.2018 & 0.1822 \\
PPS-G/10\%PA46 & 60 & 0.3234 & 0.2916 & 0.2687 \\
& 90 & 0.3042 & 0.2413 & 0.2225 \\
& 120 & 0.2778 & 0.2239 & 0.2011 \\
PPS-G/20\%PA46 & 60 & 0.3467 & 0.3266 & 0.3033 \\
& 90 & 0.3294 & 0.2824 & 0.2571 \\
& 120 & 0.3018 & 0.2591 & 0.2375 \\
PPS-G/50\%PA46 & 60 & 0.4144 & 0.3786 & 0.3484 \\
& 90 & 0.3866 & 0.3274 & 0.2966 \\
& 120 & 0.3412 & 0.3024 & 0.2856 \\
& 60 & 0.4823 & 0.4461 & 0.4192 \\
PA46 & 90 & 0.4266 & 0.3808 & 0.3515 \\
& 120 & 0.3908 & 0.3644 & 0.3264 \\
\hline
\end{tabular}

The variation of the coefficient of friction with sliding distance for PPS-G, PPS-G/10\%PA46, PPS-G/20\%PA46, PPS-G/50\%PA46 and PA46 polymers performed under $90 \mathrm{~N}$ load and $1.0 \mathrm{~m} / \mathrm{s}$ sliding speed is given in Fig. 2. It is clearly seen from this graph, that the coefficient of friction curves for PPS-G, PA46 and their blends increases rapidly beginning the test at running-in period and reaches more stable course within the steady state period. During the running-in period, wear debris are formed between the contact surface, and the wear debris become compacted and adhered on the disc surface lowering coefficient of friction in the steady-state period [26]. Similar results were obtained by Chen et. al [12] and Zhou et. al [4]. 


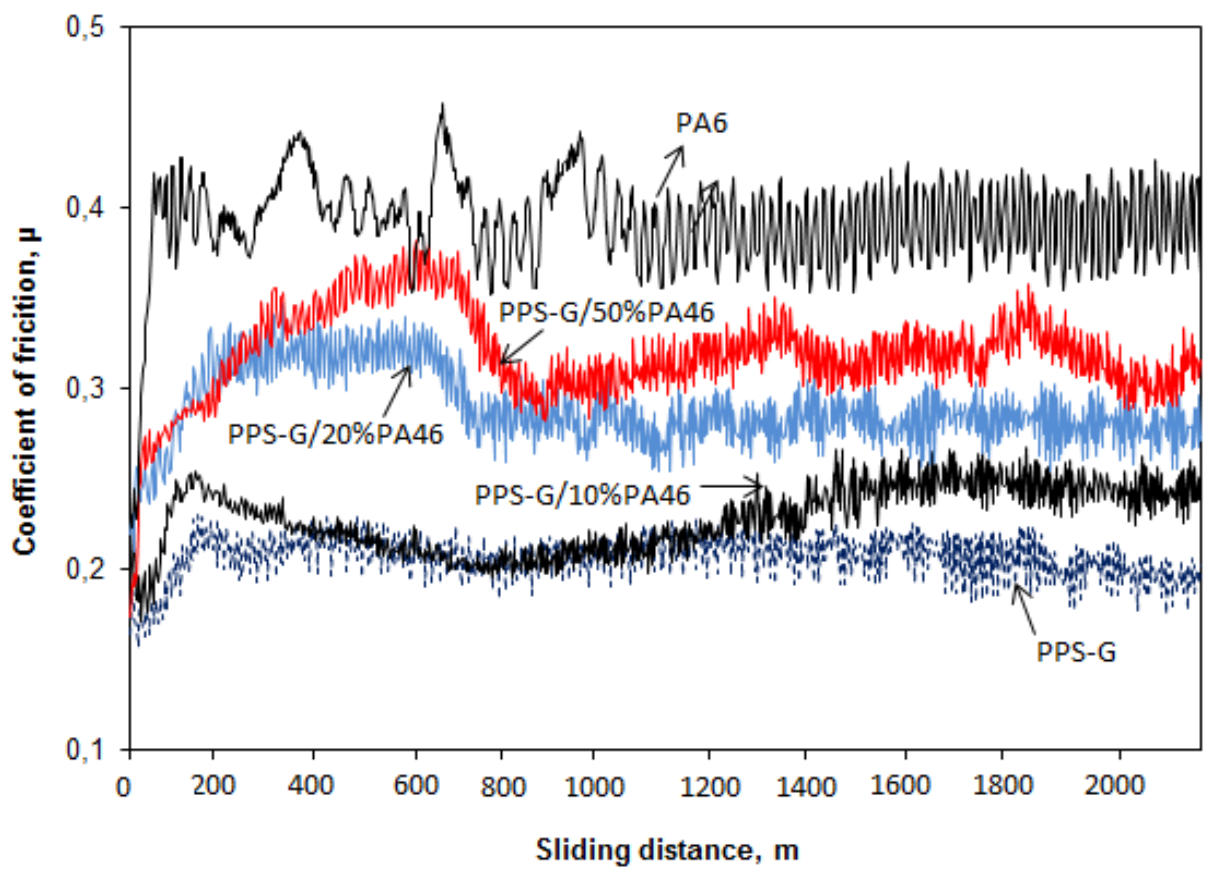

Fig. 2 Variation of coefficient of friction with sliding distance for PPS-G, PPSG/10\%PA46, PPS-G/20\%PA46, PPS-G/50\%PA46 and PA46 polymers (sliding speed: 1:0 m/s, Applied load: 90N).

If the chart is carefully considered, the overall trend for the coefficient of friction of PA46/PPS-G blends is similar, but coefficient of friction of PA46 is quite high than the PPS$G$ and PPS-G/PA46 blends, especially in the steady state. It was found that the coefficient of friction for PPS-G and PA46/PPS-G blends and for PA46, was between 0.2-0.35 and was 0.4 respectively.

Figs. 3 and 4 gives the variation of the coefficients of friction for PPS-G, PPS-G/10\%PA46, PPS-G/20\%PA46, PPS-G/50\%PA46 and PA46 polymers accordance to the applied load and sliding speeds, respectively. In Fig. 3 for PPS-G, PPS-G/10\%PA46, PPS-G/20\%PA46, PPS-G/50\%PA46 and PA46 polymers at $1.0 \mathrm{~m} / \mathrm{s}$ sliding speeds, the coefficient of friction decreases linearly while the load increases. These results are adjusted with the past studies which had been completed by Unal [27], Yuji [28], Jiang [29], Zhou [4] and Wang [16]. In the case of PPS-G, PPS-G/10\%PA46, PPS-G/20\%PA46, PPS-G/50\%PA46 and PA46, there is an average decrease result $22 \%, 23 \%, 21 \%, 20 \%$ and $18 \%$ in the coefficient of friction values while the applied load increases, respectively. The contact temperature between polymer and steel disc surfaces increased because of the increase in the applied load, which resulted in two different effects on the coefficient of friction. The first one, the real contact area increased between surfaces and then the coefficient of friction increased. The second, the shear strength decreased and thus the coefficient of friction decreased [16]. 


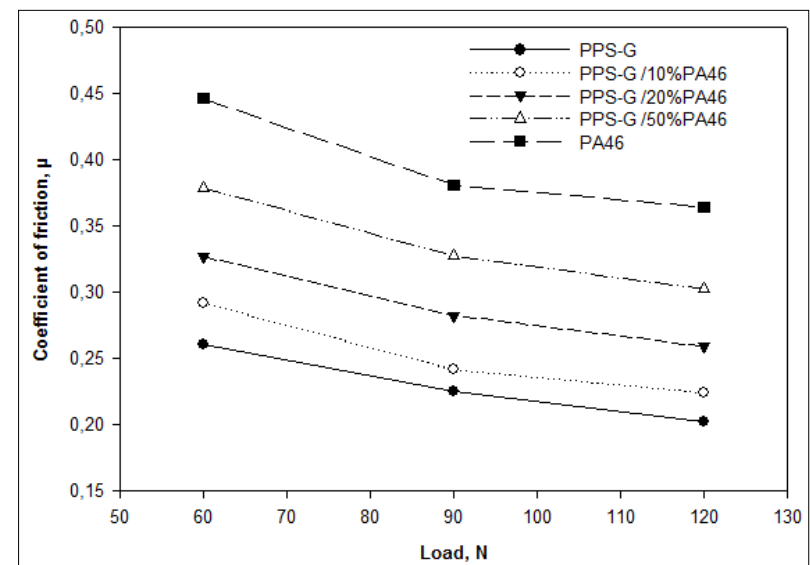

Fig. 3 Variation of coefficient of friction with applied load for PPS-G, PPS-G/10\%PA46, PPS-G/20\%PA46, PPS-G/50\%PA46 and PA46 polymers (Sliding speed: $1.0 \mathrm{~m} / \mathrm{s}$ ).

In Fig. 4 for PPS-G, PA46 and their blends at $90 \mathrm{~N}$ applied load, the coefficient of friction decreases linearly while the sliding speed increases. For PPS-G, PPS-G/10\%PA46, PPSG/20\%PA46, PPS-G/50\%PA46 and PA46, there is an average decrease of approximately $30 \%, 26 \%, 21 \%, 23 \%$ and $17 \%$ in the coefficient of friction values while the sliding speed increase from $0.5 \mathrm{~m} / \mathrm{s}$ to $1.5 \mathrm{~m} / \mathrm{s}$. It is clear from these graphs that the sliding speed influence is much higher than the applied load. The similar results were obtained by Zhou [4] and Zhang [24]. Furthermore, with the increase of the content of PA46 polymer, the coefficient of friction of PPS-G/PA46 blends increases.

Table 3 shows the specific wear rate and weight loss values in PPS-G, PPS-G/10\%PA46, PPS-G/20\%PA46, PPS-G/50\%PA46 and PA46 polymers tested under 60, 90 and $120 \mathrm{~N}$ load, at 0.5, 1.0 and $1.5 \mathrm{~m} / \mathrm{s}$ speeds and for $2000 \mathrm{~m}$ sliding distance. To determine the wear rate of the materials, the samples are weighed with a precision scale before and after the wear test. By calculating the difference between the initial weight and the final weight, the wear loss value of the sample is found for the determined conditions. The wear loss value is used to find the specific wear rates of materials by using the formulation in Eq. 2 .

$$
W_{a}=\frac{\Delta_{m}}{S \cdot \rho \cdot F_{N}}
$$

Here, $W_{a}$ is wear rate, $\Delta_{m}$ is wear loss, $S$ is slide distance, $\rho$ is density of materials and $F_{N}$ is normal force. 


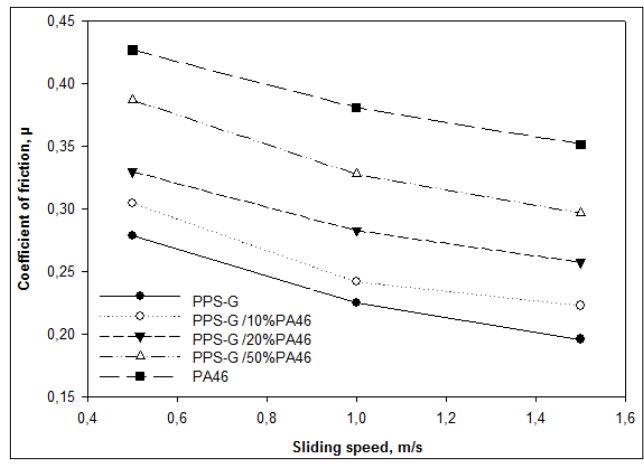

Fig. 4 Variation of coefficient of friction with sliding speed for PPS-G, PPS-G/10\%PA46, PPS-G/20\%PA46, PPS-G/50\%PA46 and PA46 polymers (Applied load: $90 \mathrm{~N}$ ).

Table 3 Specific wear rates and weight loss values for PPS, PPS/10\%PA46, PPS/20\%PA46, PPS/50\%PA46 and PA46 polymers tested at different load and sliding speed values.

\begin{tabular}{|c|c|c|c|c|c|c|c|}
\hline \multirow{3}{*}{ Materials } & \multirow{3}{*}{$\begin{array}{l}\text { Load } \\
(\mathrm{N})\end{array}$} & \multicolumn{6}{|c|}{ Speed (m/s) } \\
\hline & & 0.5 & 0.5 & 1.5 & 0.5 & 0.5 & 1.5 \\
\hline & & \multicolumn{3}{|c|}{ Weight loss (g) } & \multicolumn{3}{|c|}{ Specific wear rate $\left(\mathrm{m}^{2} / \mathrm{N}\right)$} \\
\hline \multirow{3}{*}{ PPS-G } & 60 & 0,0017 & 0,0019 & 0,0021 & $9.023 \mathrm{E}^{-15}$ & $\begin{array}{c}1.008 \mathrm{E}^{-} \\
14\end{array}$ & $1.114 \mathrm{E}^{-14}$ \\
\hline & 90 & 0,0031 & 0,0042 & 0,0049 & $1.096 \mathrm{E}^{-14}$ & $\begin{array}{c}1.486 \mathrm{E}^{-} \\
14\end{array}$ & $1.733 \mathrm{E}^{-14}$ \\
\hline & 120 & 0,0044 & 0,0061 & 0,0071 & $1.167 \mathrm{E}^{-14}$ & $\begin{array}{c}1.618 \mathrm{E}^{-} \\
14\end{array}$ & $1.884 \mathrm{E}^{-14}$ \\
\hline \multirow{3}{*}{$\begin{array}{c}\text { PPS- } \\
\text { G/10\%PA46 }\end{array}$} & 60 & 0,0027 & 0,0029 & 0,0034 & $1.490 \mathrm{E}^{-14}$ & $\begin{array}{c}1.600 \mathrm{E}^{-} \\
14\end{array}$ & $1.876 \mathrm{E}^{-14}$ \\
\hline & 90 & 0,0043 & 0,0049 & 0,0056 & $1.582 \mathrm{E}^{-14}$ & $\begin{array}{c}1,802 \mathrm{E}^{-} \\
14\end{array}$ & $2.060 \mathrm{E}^{-14}$ \\
\hline & 120 & 0,0061 & 0,0072 & 0,0084 & $1.683 \mathrm{E}^{-14}$ & $\begin{array}{c}1.986 \mathrm{E}^{-} \\
14\end{array}$ & $2.317 \mathrm{E}^{-14}$ \\
\hline \multirow{3}{*}{$\begin{array}{c}\text { PPS- } \\
\text { G/20\%PA46 }\end{array}$} & 60 & 0,0035 & 0,0037 & 0,0041 & $2.053 \mathrm{E}^{-14}$ & $\begin{array}{c}2.171 \mathrm{E}^{-} \\
14\end{array}$ & $2.406 \mathrm{E}^{-14}$ \\
\hline & 90 & 0,0054 & 0,0058 & 0,0066 & $2.112 \mathrm{E}^{-14}$ & $\begin{array}{c}2.269 \mathrm{E}^{-} \\
14\end{array}$ & $2.582 \mathrm{E}^{-14}$ \\
\hline & 120 & 0,0078 & 0,0091 & 0,0104 & $2.288 \mathrm{E}^{-14}$ & $\begin{array}{c}2.670 \mathrm{E}^{-} \\
14\end{array}$ & $3.051 \mathrm{E}^{-14}$ \\
\hline \multirow{3}{*}{$\begin{array}{c}\text { PPS- } \\
\text { G/50\%PA46 }\end{array}$} & 60 & 0,0039 & 0,0046 & 0,0051 & $2.425 \mathrm{E}^{-14}$ & $\begin{array}{c}2.860 \mathrm{E}^{-} \\
14\end{array}$ & $3.171 \mathrm{E}^{-14}$ \\
\hline & 90 & 0,0062 & 0,0073 & 0,0085 & $2.570 \mathrm{E}^{-14}$ & $\begin{array}{c}3.026 \mathrm{E}^{-} \\
14\end{array}$ & $3.524 \mathrm{E}^{-14}$ \\
\hline & 120 & 0,0084 & 0,0103 & 0,0117 & $2.611 \mathrm{E}^{-14}$ & $\begin{array}{c}3.202 \mathrm{E}^{-} \\
14\end{array}$ & $3.638 \mathrm{E}^{-14}$ \\
\hline \multirow{3}{*}{ PA46 } & 60 & 0,0041 & 0,0051 & 0,0059 & $2,895 \mathrm{E}^{-14}$ & $\begin{array}{c}3.601 \mathrm{E}^{-} \\
14\end{array}$ & $4.166 \mathrm{E}^{-14}$ \\
\hline & 90 & 0,0063 & 0,0079 & 0,0092 & 2. $961 \mathrm{E}^{-14}$ & $\begin{array}{c}3.719 \mathrm{E}^{-} \\
14\end{array}$ & $4.331 \mathrm{E}^{-14}$ \\
\hline & 120 & 0,0086 & 0,0108 & 0,0124 & $3.036 \mathrm{E}^{-14}$ & $\begin{array}{c}3.813 \mathrm{E}^{-} \\
14\end{array}$ & $4.378 \mathrm{E}^{-14}$ \\
\hline
\end{tabular}


Figs. 5 and 6 illustrate the variation of specific wear rate accordance to the applied load and sliding speed, respectively. In general, the specific wear rate for PPS-G, PPSG/10\%PA46, PPS-G/20\%PA46, PPS-G/50\%PA46 and PA46 polymers were in the order of $10^{-14} \mathrm{~m}^{2} / \mathrm{N}$. The lowest wear rate is for PPS-G with a value of $9.02 \times 10^{-15} \mathrm{~m}^{2} / \mathrm{N}$ while the highest wear rate is for PA46 with a value of $4.37 \times 10^{-15} \mathrm{~m}^{2} / \mathrm{N}$. The wear rates of PA46, PPSG/10\%PA46, PPS-G/20\%PA46 and PPS-G/50\%PA46 are 60, 51, 38 and 18 times lower than that of PPS-G at $1.0 \mathrm{~m} / \mathrm{s}$ sliding speed and $90 \mathrm{~N}$ applied load, respectively. For PPS-G and its blends performed in this study within the applied load range of 60-120 MPa, the specific wear rates are increased with the increase in the applied load.

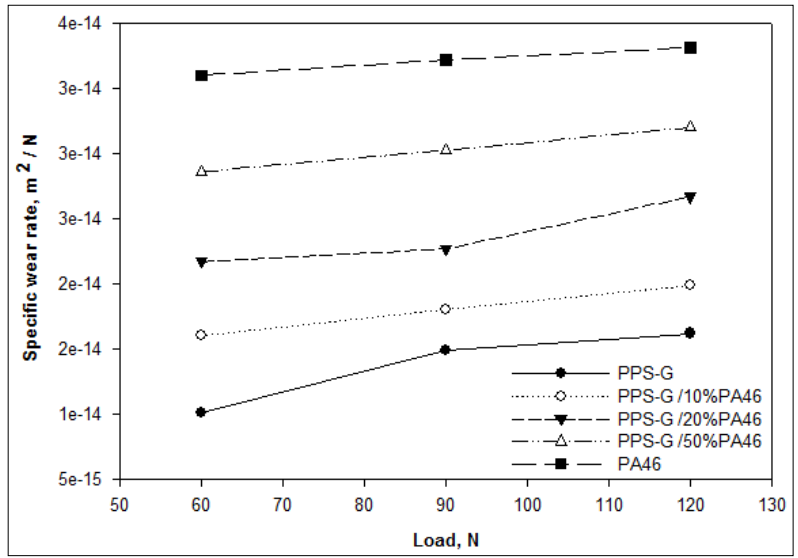

Fig. 5 Variation of specific wear rate with applied load for PPS-G, PPS-G/10\%PA46, PPS-G/20\%PA46, PPS-G/50\%PA46 and PA46 polymers (Sliding speed: $1.0 \mathrm{~m} / \mathrm{s}$ ).

In Fig. 6 the specific wear rate values for PPS-G, PPS-G/10\%PA46, PPS-G/20\%PA46, PPSG/50\%PA46 and PA46 polymers increase linearly while the sliding speed increases. In case of PPS-G, PPS-G/10\%PA46, PPS-G/20\%PA46, PPS-G/50\%PA46 and PA46, there are about 36\%, 23\%, \%18, \%27 and 31\% increase in specific wear rate from $0.5 \mathrm{~m} / \mathrm{s}$ to 1.5 $\mathrm{m} / \mathrm{s}$ in the sliding speed at $90 \mathrm{~N}$ applied load, respectively. All the findings clearly match with the earlier studies results obtained by Unal [30], Zhang et al. [26] and Wang et al. [16].

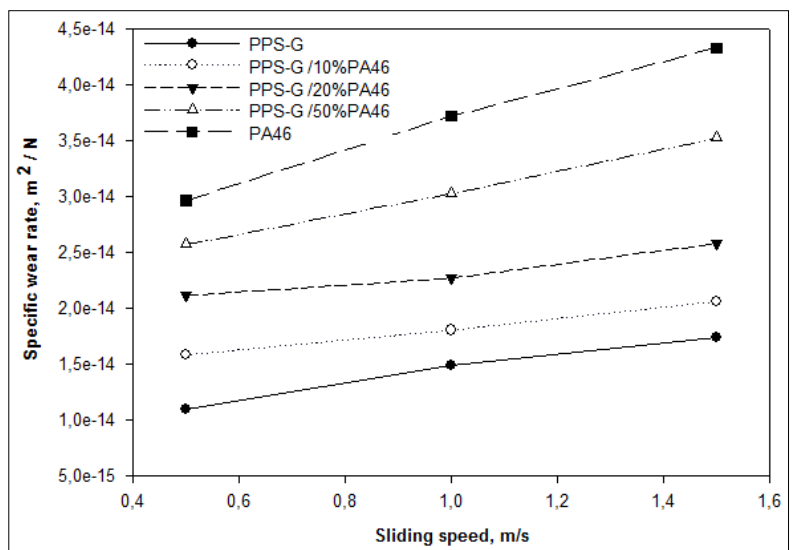

Fig. 6 Variation of specific wear rate with sliding speed for PPS-G, PPS-G/10\%PA46, PPS-G/20\%PA46, PPS-G/50\%PA46 and PA46 polymers (Applied load: 90N). 
The optical microscopy examination, as seen on Fig. 7 of the pin and disc surfaces of PPSG, PA46 and their blends in dry conditions, at $60 \mathrm{~N}$ load and at $1.0 \mathrm{~m} / \mathrm{s}$ sliding speed are given in Fig. 7. It is clear from the disc surface (in Fig. 7.a) that a good transfer film layer was formed for PPS-G polymer while the transfer film layer got worse with the increase of the content of PA46 (in Fig. 7.h). In the PPS-G polymer, the transfer film layer was effective on the entire surface, whereas in the PA46 added PPS-G blends; the transfer film layer was irregularly and locally shaped. This is thought to be due to the high specific wear rate of the PA46 polymer and increases the PPS-G blends specific wear rate with the addition increasing amount of PA46. For PA46 pin materials (in Fig. 7.j), the tested surface of the samples showed that the slip was occurred with wider and deeper grooves. However, these grooves were reduced in the PPS-G polymer due to the homogeneous transfer film layer. While a softer surface was obtained in the PPS-G/10\%PA46 and PPS-G/20\%PA46 blends, it was determined that numerous grooves were formed in the shear direction due to the increasing amount of PA46. The increased friction heat and deformed transfer film layer may deteriorate the tribological properties of PPS-G/PA46 blends. Consequently, the formation of the transfer film layer on the counter disc affected the wear and friction mechanism of PPS-G/PA46 blends.

Materials

Disc

Pin
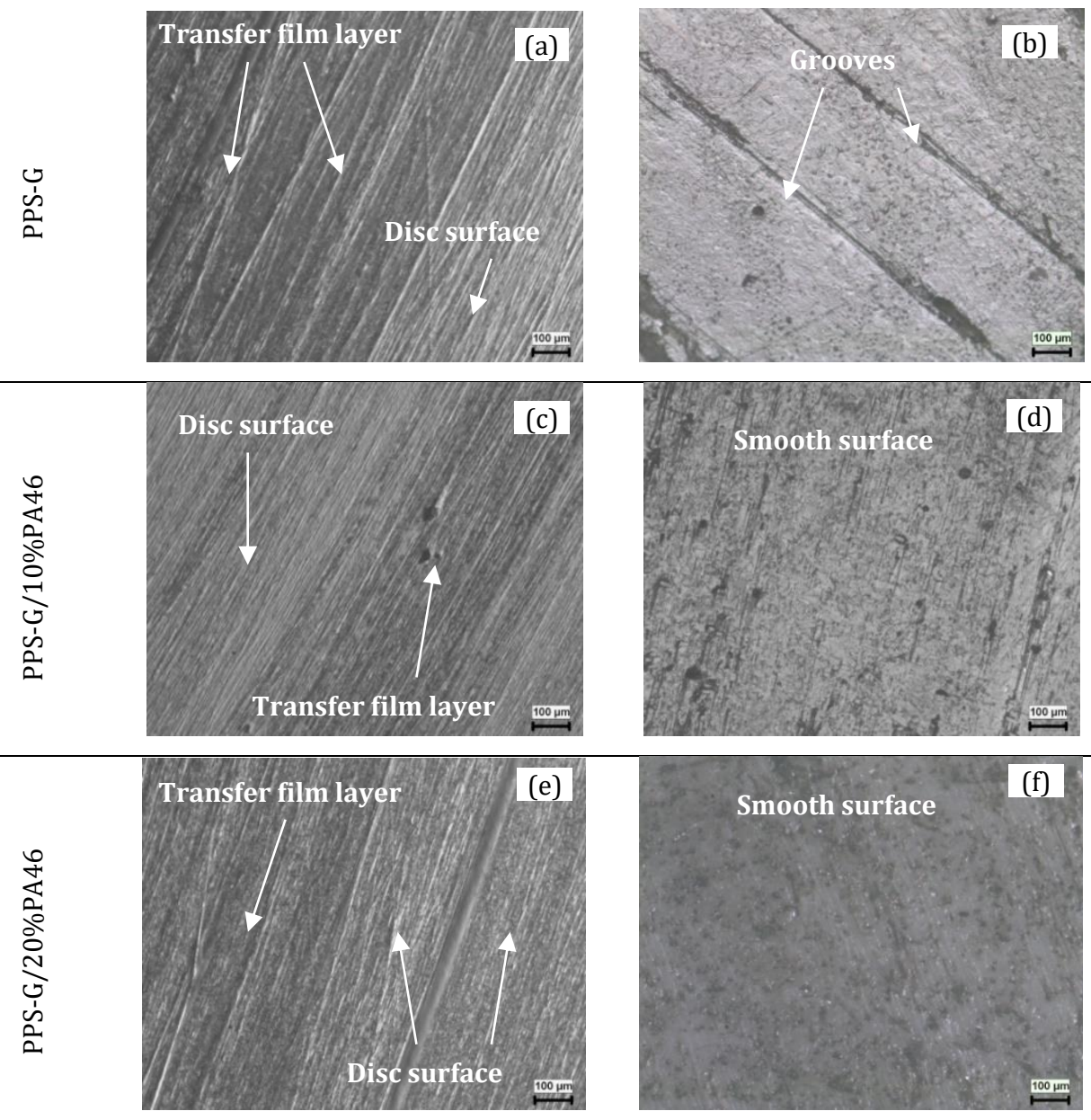


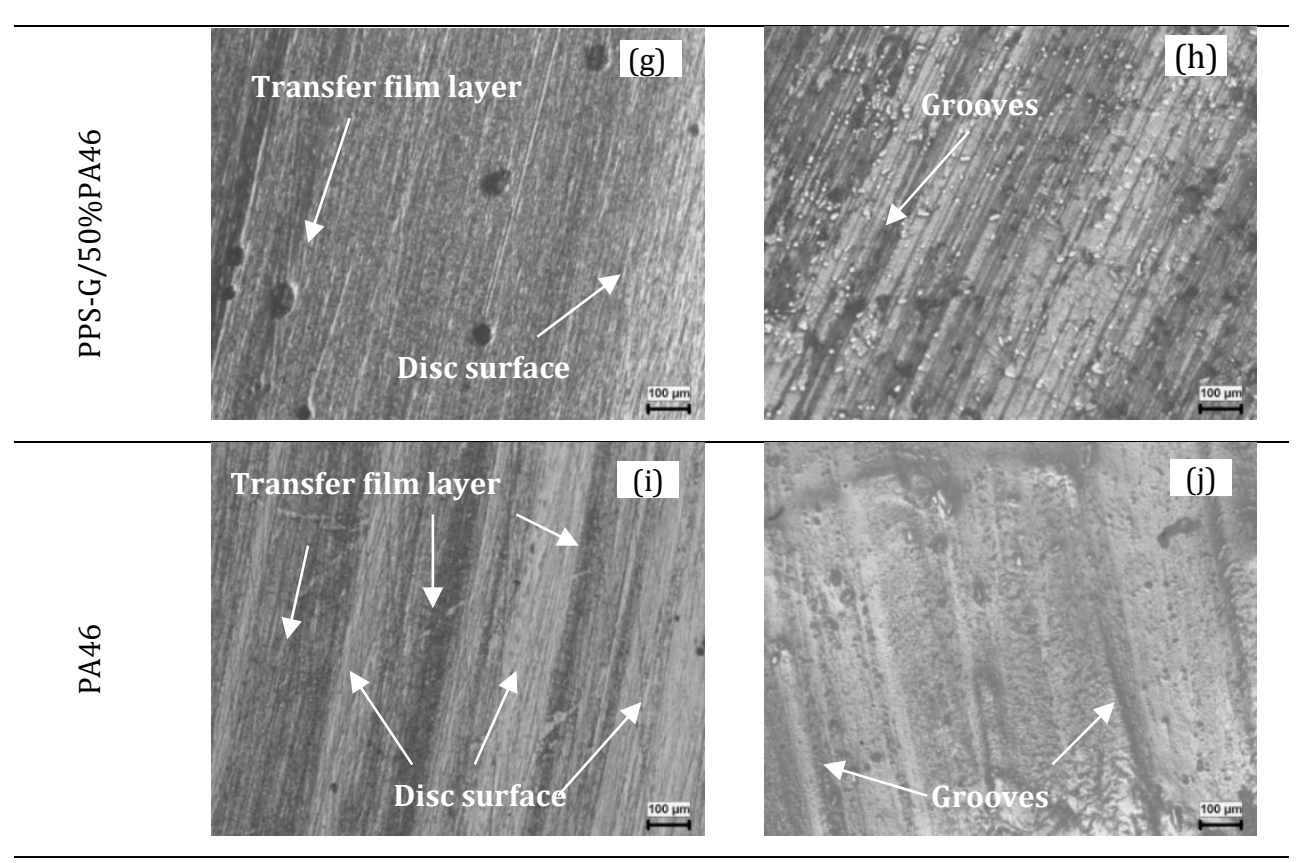

Fig. 7 Microscopy of pin-and disc surfaces of PPS-G, PA46 and their blends.

\section{Conclusions}

The tribological performance test of originally 40 wt.\% fiber glass reinforced polyphenylene sulfide (PPS-G) and polyamide 46 (PA46) blends reveals the following conclusions:

The wear rates of PA46, PPS-G and their blends were in the order of $10^{-14} \mathrm{~m}^{2} / \mathrm{N}$.

Accordance to the applied load and sliding speed parameters, the friction coefficient values decrease while specific wear rates of PA46, PPS-G and their blends increase. Although the coefficient of friction is decrease, the high coefficient of friction of PA46 polymer and its negative effects on the PPS-G blends are clearly seen.

The highest specific wear rate was with a value of $4.37 \times 10^{-14} \mathrm{~m}^{2} / \mathrm{N}$ for PA46 and the lowest wear rate was with a value $9.02 \times 10^{-15} \mathrm{~m}^{2} / \mathrm{N}$ for PPS-G polymer. As the amount of PA46 increases, the specific wear rates of PPS-G blends also increase.

When the general tendencies investigated, changes in sliding speed had the greatest effect on friction coefficient and specific wear rate, that is, the biggest impact factor was the sliding speed.

All the coefficient of friction and specific wear results of the produced polymer blend varies between the values of neat PPS-G and PA46 materials according to the addition percentage.

The transfer film layer affects the wear and friction mechanism of PPS-G/PA46 blends.

\section{Acknowledgements}

This study was carried out with the contributions of Kütahya Dumlupınar University Scientific Research Projects Program. Project number: 2013/11. 


\section{References}

[1] Zhang M, Zeng H, He Y, Mai K. Effect of a polyaryletherketone-bearing bulky substituent on the non-isothermal crystallization kinetics of polyphenylene sulfide. Thermochim Acta, 1995; 257: 183 - 188. https://doi.org/10.1016/0040-6031(94)02206-4

[2] Choi J, Lim S, Kim J, Choe CR. Studies of an epoxy-compatibilized poly (phenylene sulfide)/polycarbonate blend. Polymer, 1997; 38: 4401 - 4406. https://doi.org/10.1016/S0032-3861(96)01032-4

[3] Gopakumar TG, Ghadage RS, Ponrathnam S, Rajan CR, Fradet A. Poly (phenylene sulfide)/liquid crystalline polymer blends: 1 . Non-isothermal crystallization kinetics. Polymer, 1997; 38: 2209 - 2214. https://doi.org/10.1016/S0032-3861(96)00777-X

[4] Zhou S, Zhang Q, Wu C, Huang J. Effect of carbon fiber reinforcement on the mechanical and tribological properties of polyamide6/polyphenylene sulfide composites. Material Design, 2013; 44: 493 - 499. https://doi.org/10.1016/j.matdes.2012.08.029

[5] Yang J, Xu T, Lu A, Zhang Q, Tan H, Fu Q. Preparation and properties of poly (polyphenylene sulfide)/multiwall carbon nanotube composites obtained by melt compounding. Composite Science and Technology, 2009; 69: 147 - 153. https://doi.org/10.1016/j.compscitech.2008.08.030

[6] Schuster M, Araujo CCD, Atanasov V, Andersen HT, Kreuer KD, Maier J. Highly sulfonated poly (phenylene sulfone): preparation and stability issues. Macromolecules, 2009; 42: 3129 - 3137. https://doi.org/10.1021/ma900333n

[7] Wang J, Li KX, He HW, Wang JL, Sun GH. Kinetic and thermodynamics analysis of water absorption in unidirectional fiber reinforced composites by polyethersulphone and polyphenylene sulfide. Colloids Surfaces A, 2011; 377: $330 \quad-335$. https://doi.org/10.1016/j.colsurfa.2011.01.009

[8] Zou H, Ning N, Su R, Zhang Q, Fu Q. Manipulating the phase morphology in PPS/PA66 blends using clay. Journal of Applied Polymer Science, 2007; 106: 2238 - 2250. https://doi.org/10.1002/app.26880

[9] Ana M, Pascual D, Naffakh M. Towards the development of poly (phenylene sulphide) based nanocomposites with enhanced mechanical, electrical and tribological properties. Material Chemistry and Physics, 2012; 135: 348 - 357. https://doi.org/10.1016/i.matchemphys.2012.04.057

[10] Ana M, Pascual D, Naffakh M. Enhancing the thermo mechanical behaviour of poly(phenylene sulphide) based composites via incorporation of covalently grafted carbon nanotubes. Composites Part A-Applied Science, 2013; 54: 10 - 19. https://doi.org/10.1016/i.compositesa.2013.06.018

[11] Deng S, Cao L, Lin Z, Qiu W, Liang K, Li W. Nanodiamond as an efficient nucleating agent for polyphenylene sulfide. Thermochim Acta, 2014; 584: 51 - 57. https://doi.org/10.1016/i.tca.2014.03.017

[12] Chen Z, Li T, Yang Y, Liu X, Lv R. Mechanical and tribological properties of PA/PPS blends. Wear, 2004; 257: 696 - 707. https://doi.org/10.1016/j.wear.2004.03.013

[13] Cong P, Xiang F, Liu X, Li T. Effect of crystalline form on the tribological properties of PA46/HDPE polyblends. Wear, 2008; 265: 1106 - 1113. https://doi.org/10.1016/i.wear.2008.03.005

[14] Scherge M, Kramlich J, Böttcher R, Hoppe T. Running-in due to material transfer of lubricated steel/PA46 (aliphatic polyamide) contacts. Wear, 2013, 301: 758 - 762. https://doi.org/10.1016/j.wear.2012.11.035

[15] Elsner P, Eyerer P, Hirth T. Polymer Engineering, Berlin, VDI-Book Springer, 2008.

[16] Wang Q, Zhang X, Pei X. Study on the synergistic effect of carbon fiber and graphite and nano particle on the friction and wear behavior of polyimide composites. Material Design, 2010; 31: 3761 - 3768. https://doi.org/10.1016/i.matdes.2010.03.017 
[17] Laigui W, Yang S, Liu W, Xue Q. An investigation of the friction and wear behaviors of polyphenylene sulfide filled with solid lubricants. Polymer Engineering and Science, 2000; 40: 1825 - 1832. https://doi.org/10.1002/pen.11314

[18] Zhao Q, Bahadur S. The mechanism of filler action and the criterion of filler selection for reducing wear. Wear, 1999; 225: 660-668. https://doi.org/10.1016/S00431648(99)00023-X

[19] Cho MH. The role of transfer film and back transfer behavior on the tribological performance of polyoxymethylene in sliding. Jounal of Mechanical Science and Technologie, 2009; 23: 2291-2298. https://doi.org/10.1007/s12206-009-0354-z

[20] Cho MH, Bahadur S, Pogosian AK. Friction and wear studies using Taguchi method on polyphenylene sulfide filled with a complex mixture of MoS2, Al20 and other $\begin{array}{llllll}\text { compounds. } \quad \text { Wear, 2005; } & \text { 258: } & 1825 & -\end{array}$ https://doi.org/10.1016/i.wear.2004.12.017

[21] Yu S, Hu H, Yin J. Effect of rubber on tribological behaviors of polyamide 66 under dry and water lubricated sliding. Wear, 2008; 265: 361 - 366. https://doi.org/10.1016/i.wear.2007.11.006

[22] https://www.eurotec-ep.com/daha-verimli-ve-akilli-arabalara-hazirlik/

[23] https://www.pagev.org/pps

[24] https://omnexus.specialchem.com/news/industry-news/polyplastics-pps-bump-offmolding-of-automotive-engine-cooling-system-000215941

[25] http://www.tpacomponents.com/uploads/pdf/en/0205_EN.pdf

[26] Zhang XR, Pei XQ, Wang QH. Friction and wear studies of polyimide composites filled with short carbon fibers and graphite and micro SiO2. Material Design, 2009; 30: 4414 - 4420. https://doi.org/10.1016/i.matdes.2009.04.002

[27] Unal H, Mimaroglu A, Serdar V. Dry sliding performance of thermoplastics against reinforced unsaturated polyester (BMC): In use in electrical contact breakers components. Wear, 2006; 261: 841 - 847. https://doi.org/10.1016/j.wear.2006.01.021

[28] Yamamoto Y, Hashimoto M. Friction and wear of water lubricated PEEK and PPS sliding contacts Part 2. Composites with carbon or glass fibre. Wear, 2004; 257: 181 189. https://doi.org/10.1016/j.wear.2003.12.004

[29] Jiang Z, Gyurova LA, Schlarb AK, Friedrich K, Zhang Z. Study on friction and wear behavior of polyphenylene sulfide composites reinforced by short carbon fibers and sub-micro TiO2 particles. Composite Science and Technologie, 2008; 68: 734 - 742. https://doi.org/10.1016/j.compscitech.2007.09.022

[30] Unal H, Sen U, Mimaroglu A. Dry sliding wear characteristics of some industrial polymers against steel counterface. Tribologie Int. 2004; 37: 727 - 732. https://doi.org/10.1016/j.triboint.2004.03.002 